\title{
The True Mechanism That Controls the Stock-Recruitment Relationship
}

\author{
Kazumi Sakuramoto \\ Department of Ocean Science and Technology, Tokyo University of Marine Science and Technology, Tokyo, Japan \\ Email:sakurak@kaiyodai.ac.jp
}

How to cite this paper: Sakuramoto, K. (2018) The True Mechanism That Controls the Stock-Recruitment Relationship. Open Access Library Journal, 5: e4341. https://doi.org/10.4236/oalib.1104341

Received: January 15, 2018

Accepted: February 25, 2018

Published: February 28, 2018

Copyright (c) 2018 by author and Open Access Library Inc.

This work is licensed under the Creative Commons Attribution International License (CC BY 4.0).

http://creativecommons.org/licenses/by/4.0/

\begin{abstract}
I propose a mechanism that controls the stock-recruitment relationship (SRR), which should replace traditional SRR models. The difference between the traditional SRR models and the model proposed herein is whether or not a density-dependent effect is assumed. The new mechanism elucidates the following: 1) why clockwise loops or anticlockwise loops are commonly observed in an actual SRR, and 2) the age at maturity (not a density-dependent effect) determines the slope of the regression line for the SRR. These cannot be explained by the traditional SRR models, the basis of which is a density-dependent effect. The new SRR mechanism can well explain the SRRs for Pacific stocks of Japanese sardine, Pacific bluefin tuna and Arctic bluefin tuna. The new SRR mechanism proposed herein should be used as a valid SRR model when the management of fishery resources is discussed. Without the adaptation of this new mechanism, fishery resource management may continue to be troubled by the lack of validity of the traditional SRR models.
\end{abstract}

\section{Subject Areas}

Marine Biology

\section{Keywords}

Pacific Bluefin Tuna, Arctic Bluefin Tuna, Pacific Stock of Japanese Sardine, Density-Dependent Effect, Stock-Recruitment Relationship

\section{Introduction}

The stock-recruitment relationship (SRR) is one of the most important topics in fishery resource management. The traditional SRR models such as the Ricker model [1], the Beverton and Holt model [2], and the hockey-stick model [3] are constructed assuming that a density-dependent effect exists between the re- 
cruitment and the spawning stock biomass (S). That is, the recruitment increases almost linearly as the $S$ increases, but the increasing rate of recruitment declines as the $S$ increases in response to a density-dependent effect. The further the $S$ increases, the more the recruitment declines; in addition, in the Ricker model the recruitment has a peak at a certain level of $S$, and in the Beverton and Holt model, the recruitment asymptotically closes to a constant value. In the hockey-stick model, the recruitment linearly increases as the $\mathrm{S}$ increases to a certain level, and when the $S$ increases beyond that level, the recruitment is constant regardless of the S. Thus, in these traditional models, the shapes of the SRR are essentially determined by the density.

These traditional models have been commonly used all over the world by not only management organizations of individual countries but also international fishery management bodies such as regional fishery management organizations (RFMOs). However, the models have faced the serious problem of determining a suitable SRR. For example, the International Scientific Committee (ISC) for Tuna and Tuna-like Species in the North Pacific Ocean, which is the international management body for Pacific bluefin tuna, Thunnus orintalis, has not been able to determine a suitable SRR model, because the SRR for Pacific bluefin tuna has no trend and no relationship has been detected between the recruitment and the $S$ for this species. The ISC concluded that the SRR for Pacific bluefin tuna is not yet known [4].

The maximum sustainable yield (MSY) theory also has a serious defect. The MSY is derived from the SRR. A surplus yield can be calculated by subtracting the replacement yield from the recruitment. The relationship between the surplus yield and $S$ shows a dome shape, and the maximum value of this relationship is the so-called MSY. The MSY is commonly used as the target of fishery resource management. In RMFOs, a "Kobe Chart" is commonly used to judge the appropriateness of the current level of tuna resources and fish intensity [5]. A Kobe Chart uses the ratios of $\mathrm{B}_{\text {current }} / \mathrm{B}_{\mathrm{MSY}}$ for the $\mathrm{x}$-axis, and $\mathrm{F}_{\text {current }} / \mathrm{F}_{\mathrm{MSY}}$ for the $\mathrm{y}$-axis; $\mathrm{B}_{\text {current }}$ and $\mathrm{B}_{\mathrm{MSY}}$ denote the current biomass and the biomass level that provides the MSY, respectively. $\mathrm{F}_{\text {current }}$ and $\mathrm{F}_{\mathrm{MSY}}$ denote the current fishing mortality coefficient and the value of the fishing mortality coefficient that gives the MSY, respectively. If the current fisheries are located at a region that satisfies $\mathrm{B}_{\text {current }} / \mathrm{B}_{\mathrm{MSY}}>1$ and $\mathrm{F}_{\text {current }} / \mathrm{F}_{\mathrm{MSY}}<1$ (that is, the current biomass is above the $\mathrm{B}_{\mathrm{MSY}}$ and the current fishing mortality coefficient is below the $\mathrm{F}_{\mathrm{MSY}}$ ), then the current fisheries intensity is judged as not overfishing and the level of resources is considered to be safe.

When the current fisheries are located at a region that satisfies $B_{\text {current }} / B_{M S Y}<1$ and $\mathrm{F}_{\text {current }} / \mathrm{F}_{\mathrm{MSY}}>1$, the current fisheries intensity is judged as overfishing, and the resource level is dangerous. This indicates that the current F should be reduced. However, the International Commission for the Conservation of Atlantic Tunas (ICCAT), which is the international organization for managing tuna in the Atlantic Ocean, suddenly stopped using the Kobe Chart for bluefin tuna re- 
sources from this year [6]. This indicates that the Kobe Chart itself has some serious defect (s) for use in management procedures, and I believe that it also means that the theory of MSY itself is questionable.

I have noted that environmental factors play an extremely important role in the SRR, and I proposed a new theory for the SRR that does not assume any density-dependent effect [7]-[13]. In this theory, the recruitment is proportionally reproduced by the $S$ and simultaneously affected by environmental conditions. Generally, environmental factors fluctuate cyclically, and the recruitment also fluctuates cyclically in response to environmental conditions. The $S$ also varies cyclically according to the fluctuations in the recruitment with a certain time lag, which is mainly determined by the fishes' age at maturity.

This new theory can elucidate both the mechanism in which clockwise loops or anticlockwise loops commonly appear in the SRR, and the mechanism underlying the concept that age at maturity determines the slope of the regression line for the SRR. I applied this theory to the Pacific stock of Japanese sardine, Sardinops melanostictus, and Pacific bluefin tuna, and I detected an increasing trend of the SRR with clockwise loops in the SRR for the Pacific stock of Japanese sardine, whereas no trend with anticlockwise loops was detected in the SRR for Pacific bluefin tuna [11]. Tanaka et al. [14] applied this theory for 24 stocks that are harvested around Japan. I applied this theory [15] for eight stocks that Myers et al. [16] analyzed. Tanaka et al. and I showed that the theory can applicable to those 24 stocks and another eight stocks. That is, when the age at maturity is low, the SRR has an increasing trend with clockwise loops; when the age at maturity is high, the SRR has a decreasing trend with anticlockwise loops.

However, the previous papers are quite complicated, and it may thus be difficult to understand the essential point of the theory. I strongly feel that a more easily understood explanation of the theory is necessary. Herein I provide a further explanation of the new SRR theory, using simple simulations.

\section{Materials and Methods}

\subsection{Data}

For Pacific bluefin tuna, the data of recruitment, the spawning stock biomass and fishing mortality coefficient from 1952 to 2012, and the mean weight by age and the growth function were used [4]. For the Pacific stock of Japanese sardine, the data of recruitment and spawning stock biomass from 1951 to 2012 were used [17] [18]. For western Atlantic bluefin tuna, Thunnus thynnus, the data of recruitment and spawning stock biomass from 1970 to 2012 were used [5].

\subsection{Simulation Model}

The model used in the simulation is as follows:

$$
\begin{gathered}
R_{t}=\cos ((\pi / T) * t)+6 \\
S_{t}=\cos ((\pi / T) *(t-m))+6
\end{gathered}
$$


Here, $R_{t}$ and $S_{t}$ denote the recruitment and the $S$ in year $t$, respectively. $T$ denotes the cycle of environmental conditions and is fixed at 8 years throughout this simulation. The notation $m$ denotes the age at maturity, and cases in which $m$ changes from $0,1,2, \cdots$ were tested in the simulations. The value 6 in Equations (1) and (2) was added to make $R_{t}$ and $S_{t}$ have positive values.

\subsection{Calculation of Weighted Mean Age at Maturities}

The weighted mean age at maturities is calculated using the following two methods. First, the biomass by age $a, B_{a}$, is calculated by Equation (3).

$$
B_{a}=N_{3} \mathrm{e}^{-0.25(a-3)} w_{a} u_{a}
$$

where $N_{3}$ denotes the number of fish at age 3-year-old, which is the first age at maturity. The notations $u_{a}$ and $w_{a}$ denote the maturity rate at age $a$ and mean weight at age $a$, respectively. The number 0.25 denotes the natural mortality coefficient. The weighted mean age at maturity is then calculated by Equation (4).

$$
\bar{m}=\sum_{3}^{25} a B_{a} / \sum_{3}^{25} B_{a}
$$

The length by age $a, L_{a}$, and the weight by age $a, W_{a}$, are calculated using the following equations [5]:

$$
\begin{gathered}
L_{a}=2.54\left(1-\mathrm{e}^{-0.517(a-0.561)}\right) \\
w_{a}=1.71 L^{3.03} / 100000
\end{gathered}
$$

Second, the weighted mean age at maturity is calculated using Equations (7) and (8). The mean weight of 5-year-old fish is $68 \mathrm{~kg}$, at which point each fish spawns approx. one million eggs [5]; the mean weight of 16-year-old fish is 276 $\mathrm{kg}$ and the each fish at that age spawns approx. ten million eggs. That is, when the body weight of the fish becomes four times larger than that of age 5, the number of eggs spawned becomes ten times larger than that of age 5. Based on this information, I assume that the relationship between body weight and the number of eggs that one fish spawns can be expressed by Equation (7), and that the weighted mean age at maturity can be calculated using Equation (8).

$$
\begin{gathered}
E_{a}=35.1 \cdot \mathrm{e}^{0.209 a} \\
\bar{m}=\sum_{3}^{25} a u_{a} E_{a} N_{a} / \sum_{3}^{25} u_{a} E_{a} N_{a}
\end{gathered}
$$

where $N_{a}, u_{a}$ and $w_{a}$ denote the number of fish at age $a$, the maturity rate at age $a$, and the mean weight at age $a$, respectively.

\section{Results}

\subsection{The Recruitment (R) Trajectory and the S Trajectory}

Figure 1(a) shows the trajectories of the recruitment (blue line) and the $S$ (red line) when the age at maturity $(m)$ is set at 0 . When $m=0$, from Equations (1) and (2), the recruitment and the $S$ coincide with each other, and the recruitment 


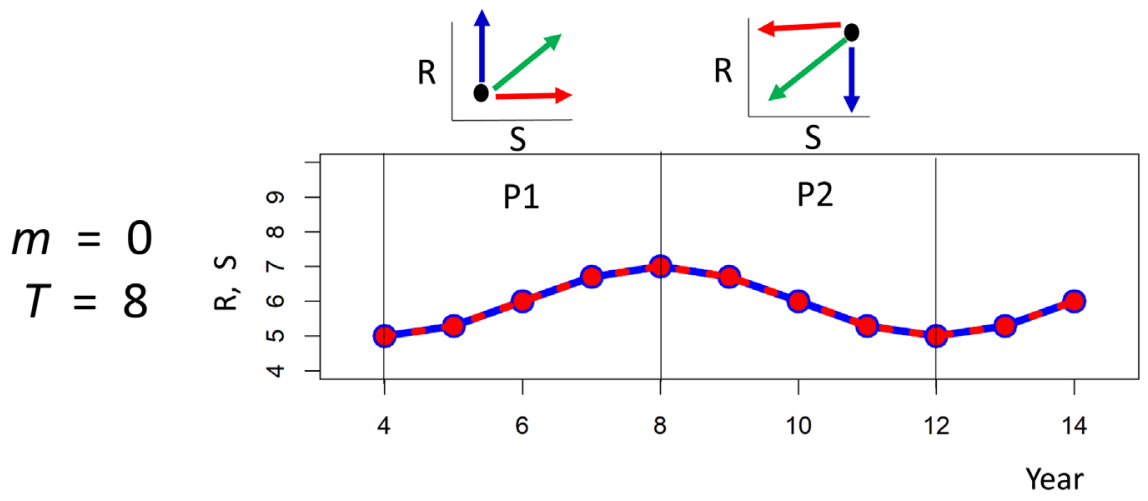

(a)
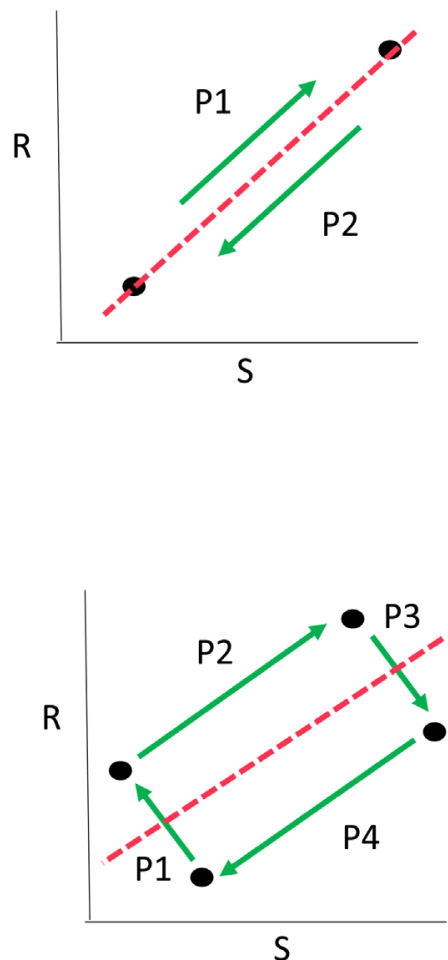

(b)

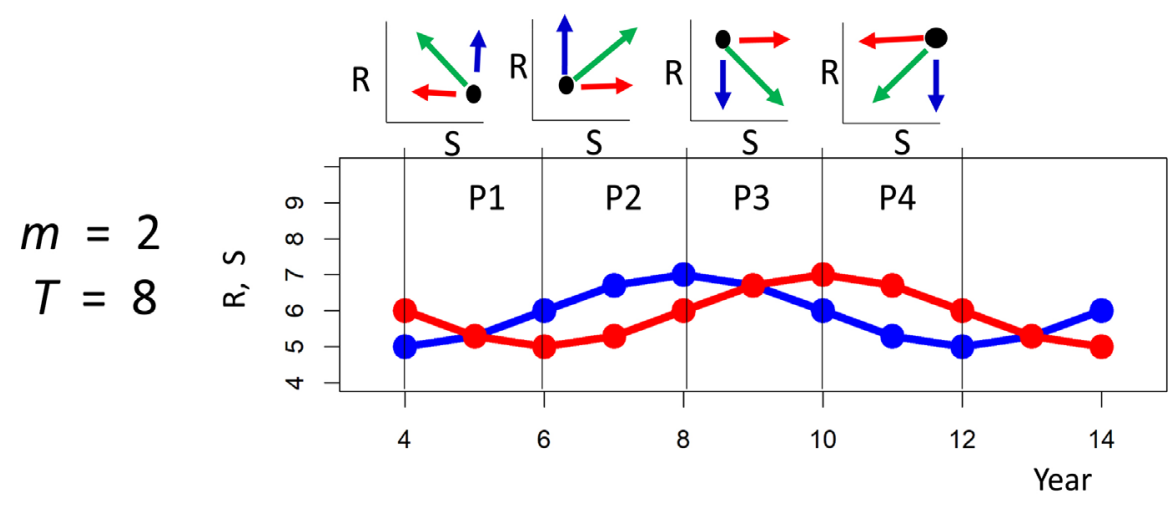

(c)
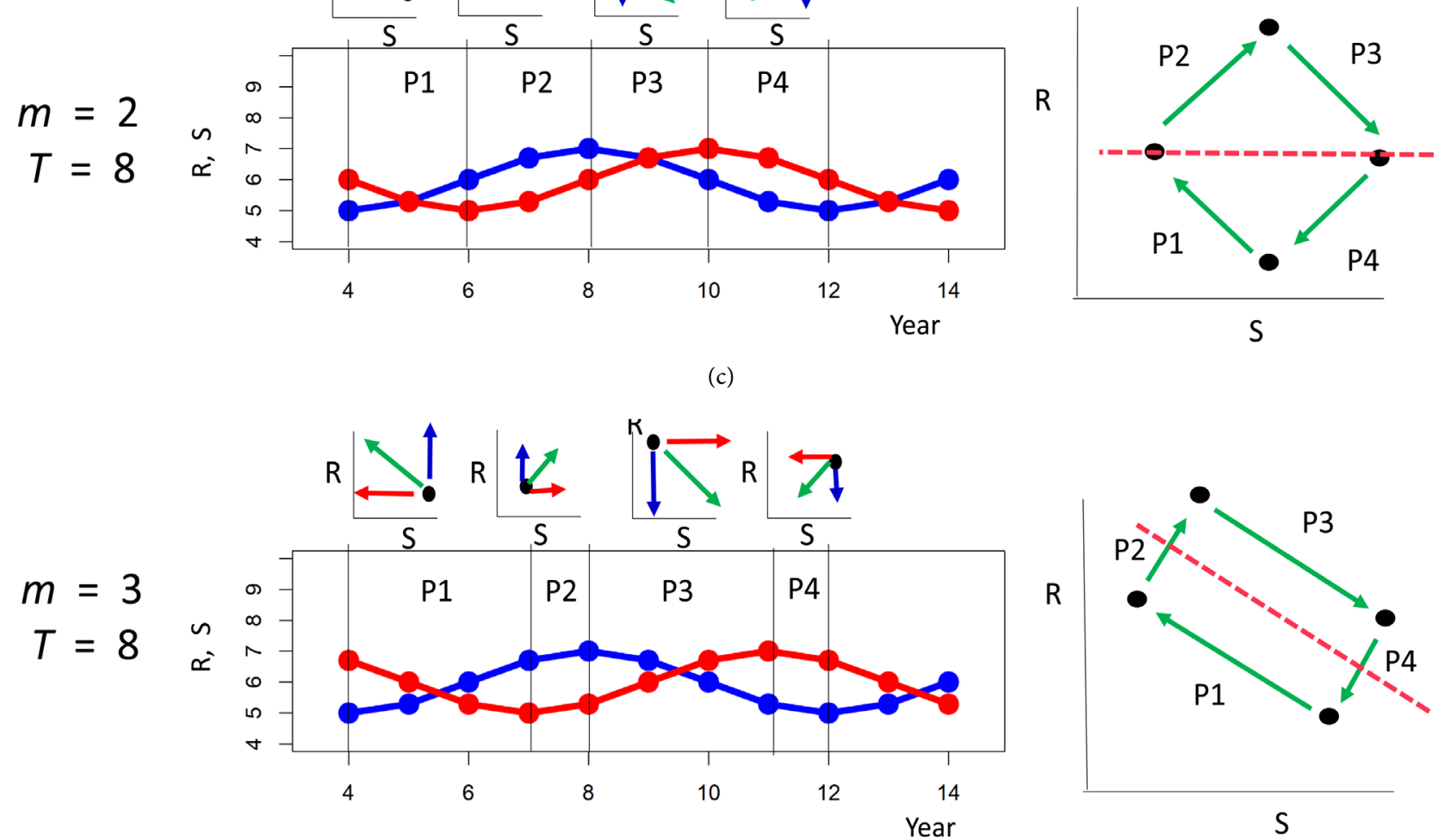

(d) 


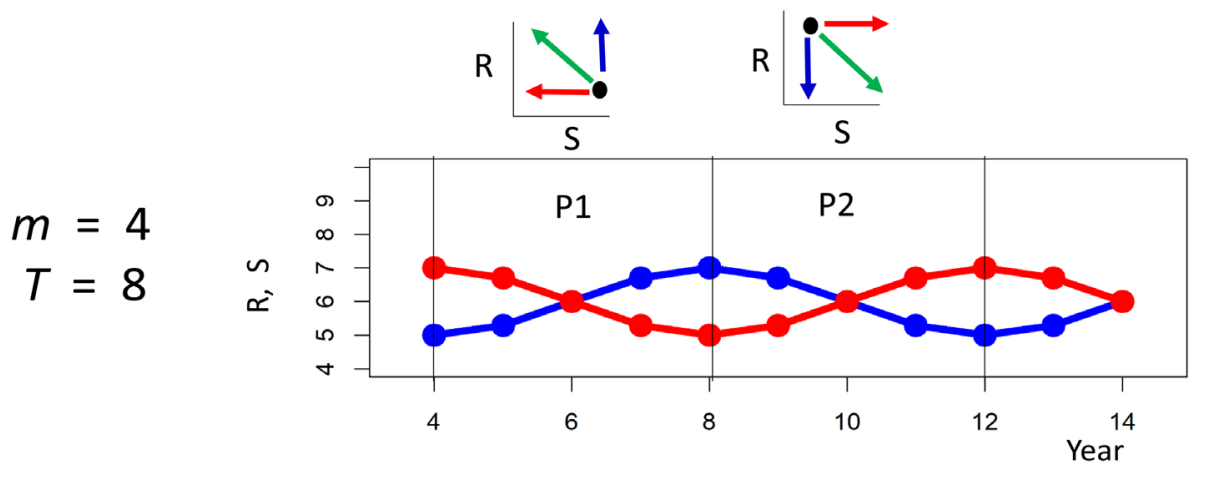

(e)

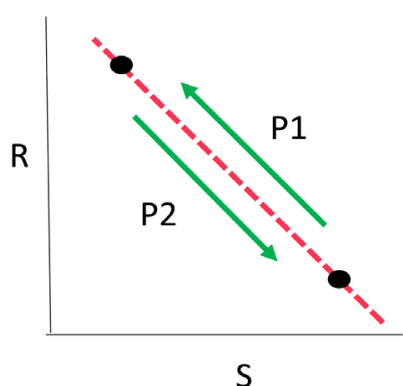

S

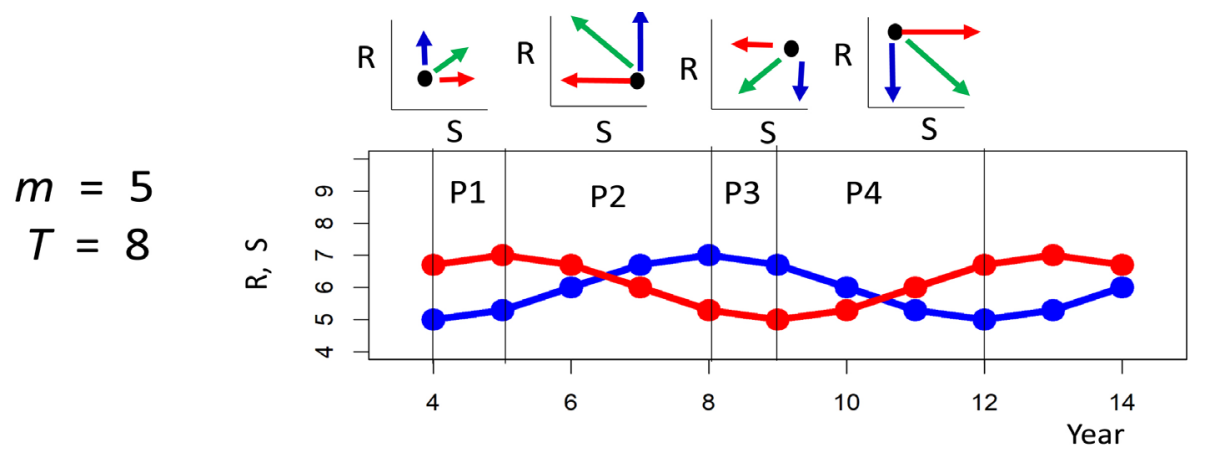

(f)
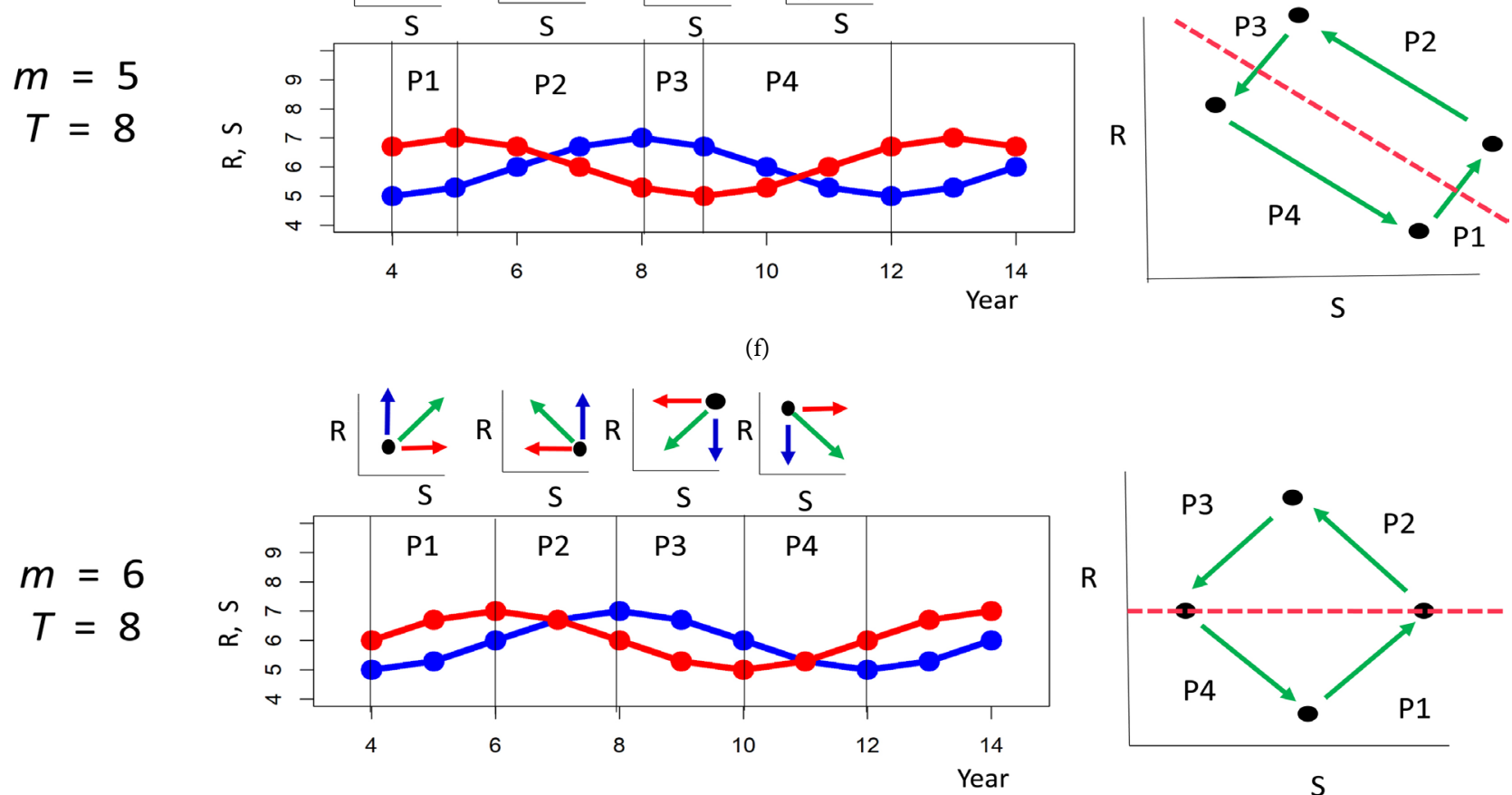

(g)
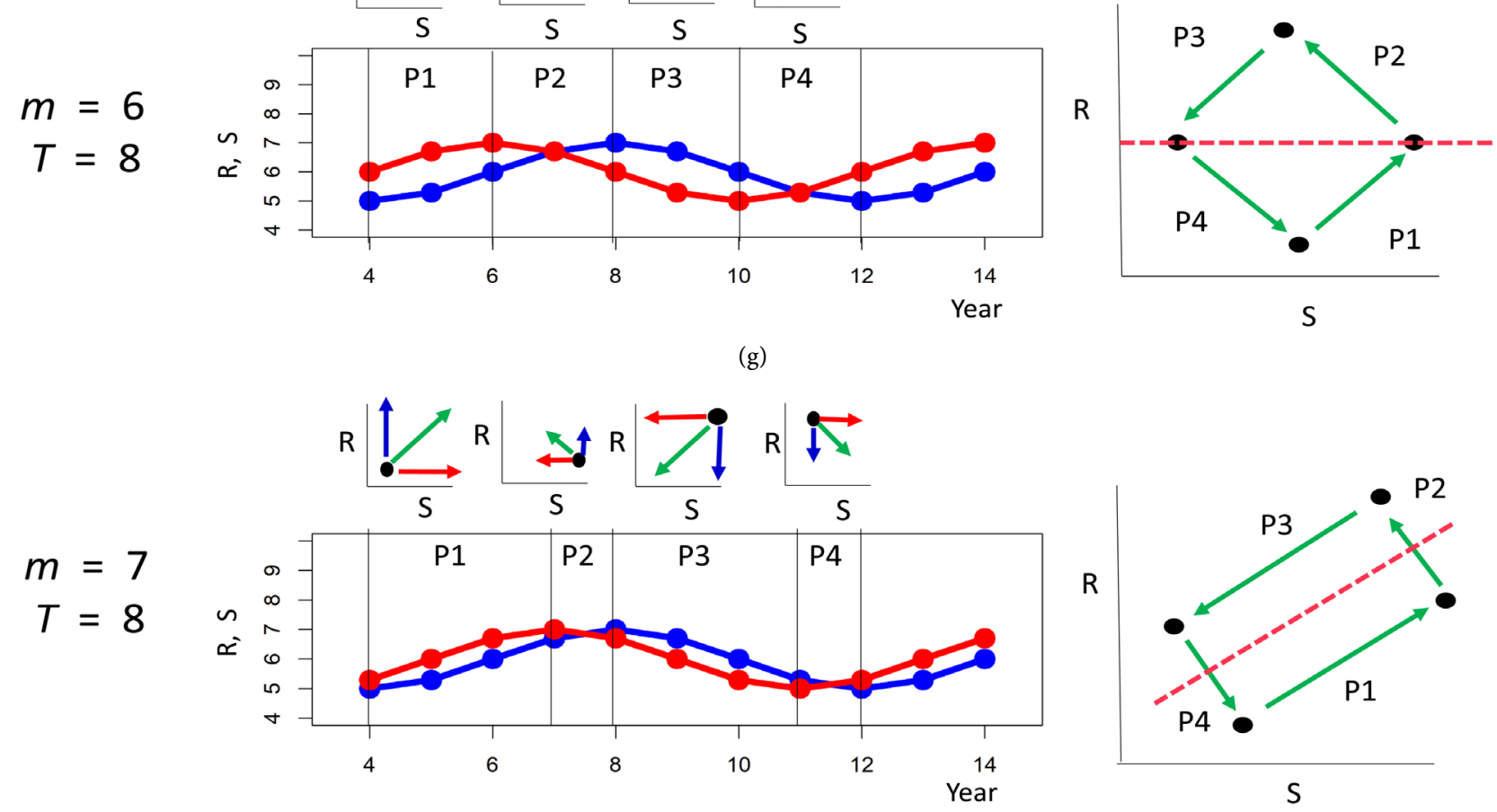

(h)

Figure 1. Left: The trajectories of the recruitment R (blue line) and the spawning stock biomass (S) (red line) when the age at maturity $(m)$ is $0,1,2, \cdots, 7$, respectively. The arrows above the $\mathrm{R}$ and $\mathrm{S}$ trajectories show the moving direction of a point (S, R) on the S-R plane. Right: The vectors of each period, P1, P2, P3 and P4. 
and $\mathrm{S}$ can be expressed with the same curve. In this simulation, the years from 4 to 12 are used as one cycle, because this makes the simulation and theory easy to explain. The 8-year trajectories from year $4-5,5-6, \cdots, 11-12$ in one cycle $T$ are divided into two periods. One is the period comprised of 4 years in which the recruitment and the $S$ are both increasing. This period is denoted as $\mathrm{P} 1$. The second period is comprised of 4 years in which the recruitment and the $S$ are both decreasing; this is denoted as P2. One cycle is composed of P1 and P2.

Figure 1(a) also shows the moving direction of a point $(S, R)$ on the $S-R$ plane. In period $\mathrm{P} 1$, the direction of vector $\mathrm{S}$ faces the right-hand side; i.e., the $\mathrm{S}$ is increasing, and the direction of vector $\mathrm{R}$ faces the upward direction, i.e., the recruitment is increasing. The point $(\mathrm{S}, \mathrm{R})$ thus moves in a "northeast" direction. In period $\mathrm{P} 2$, the direction of vector $\mathrm{S}$ faces the left-hand side; i.e., the $\mathrm{S}$ is decreasing, and the direction of vector $\mathrm{R}$ faces the downward direction, i.e., the recruitment is decreasing. The point thus moves in a "southwest" direction. The moving direction of the point is thus determined by whether or not the year belongs to period P1 or P2. Points on the S-R plane move northeast in period P1 and southwest in period P2 along the line shown by the dotted line at the right of Figure 1(a).

Figure 2(a) is the graph of the eight points $\left(S_{4}, R_{4}\right),\left(S_{5}, R_{5}\right),\left(S_{6}, R_{6}\right), \ldots,\left(S_{11}\right.$, $\left.\mathrm{R}_{11}\right)$ plotted on the $S-R$ plane in the case of $m=0$. The point $\left(S_{12}, R_{12}\right)$ is not shown because it coincides with the point $\left(\mathrm{S}_{4}, \mathrm{R}_{4}\right)$. The numbers from 4 to 11 attached near the points of the SRR trajectory denote the years that construct one cycle. When $m=0$, the slope of the regression line is unity. As shown in the right-hand side of Figure 1(a), the point $\left(S_{4}, R_{4}\right)$ moves northeast on the S-R plane along the line of which the slope is unity, and then it moves southwest along the same line.

Figure 1(b) shows the trajectories of the recruitment and $S$ when the age at maturity is set at 1 . When $m=1$, the 1 -year translated curve of the recruitment trajectory becomes the curve of $\mathrm{S}$. That is, the value of the recruitment in year $t$ becomes the value of $\mathrm{S}$ in year $t+1$. In this case the 8 years (one cycle $T$ ) is divided into four periods: P1, P2, P3 and P4. In P1, the recruitment increases but the $S$ decreases, and thus the point $(S, R)$ on the $S-R$ plane moves northwest on the $\mathrm{S}-\mathrm{R}$ plane shown above the $\mathrm{R}$ and $\mathrm{S}$ trajectories the figure. The period of $\mathrm{P} 1$ is 1 year. In $\mathrm{P} 2$, the recruitment and $\mathrm{S}$ both increase, and therefore, the point ( $\mathrm{S}$, $\mathrm{R})$ on the $\mathrm{S}-\mathrm{R}$ plane moves northeast on the S-R plane shown above the trajectories in the figure's panel (b). The length of $\mathrm{P} 2$ is 3 years.

In $\mathrm{P} 3$, the recruitment begins to decrease but the $\mathrm{S}$ still increases, and thus the point $(S, R)$ on the $S-R$ plane moves southeast on the S-R plane shown above the trajectories in panel (b). The length of $\mathrm{P} 3$ is 1 year. In P4, the recruitment and S both decrease, and therefore, $(\mathrm{S}, \mathrm{R})$ on the $\mathrm{S}-\mathrm{R}$ plane moves southwest as shown on the S-R plane shown above the trajectories in Figure 1(b). The length of P4 is 3 years. Therefore, as one cycle passes, a point $(S, R)$ on the S-R plane moves northwest in P1, northeast in P2, southeast in P3, and southwest in P4, in that 


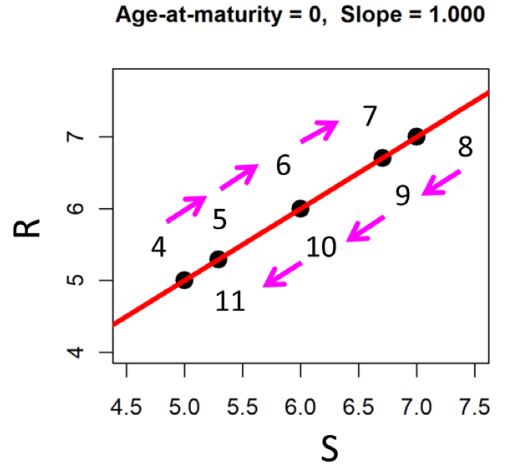

(a)

Age-at-maturity $=2$, Slope $=0.0785$

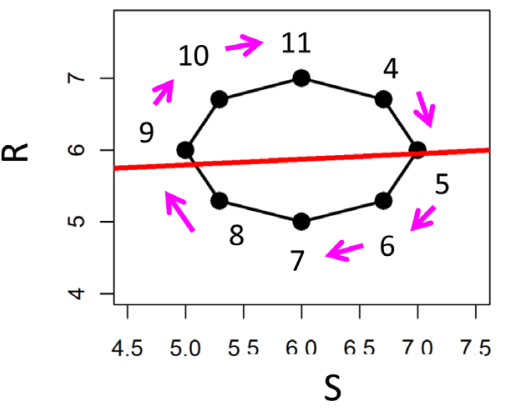

(c)

Age-at-maturity $=4$, Slope $=-1.000$

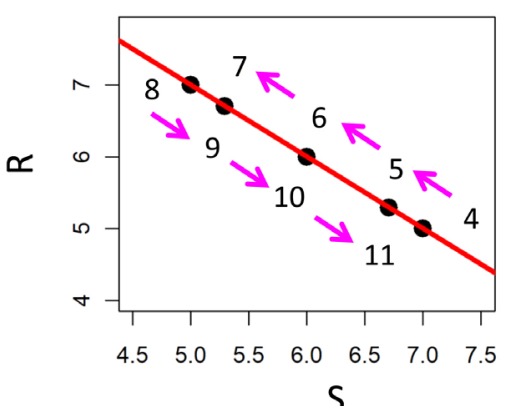

(e)

Age-at-maturity $=6$, Slope $=-0.0785$

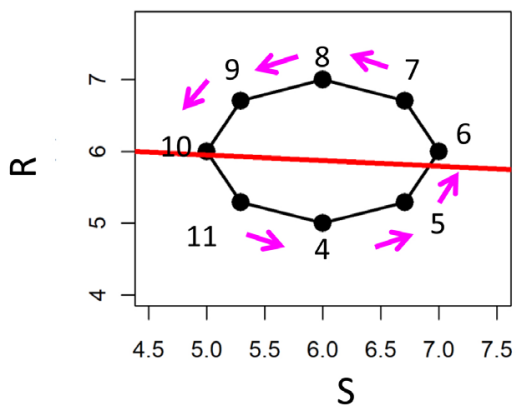

(g)

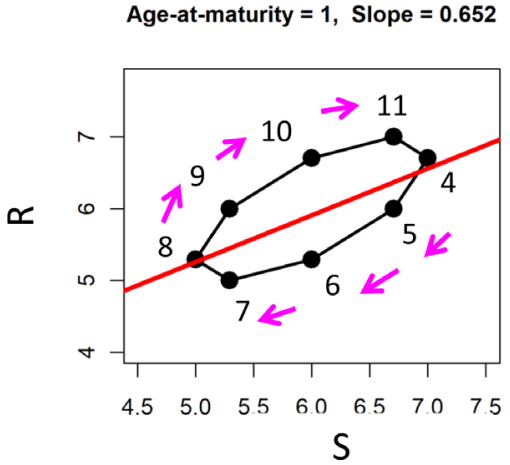

(b)

Age-at-maturity $=3$, Slope $=-0.641$

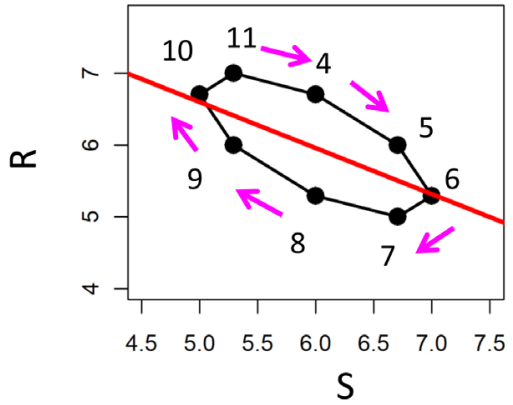

(d)

Age-at-maturity $=\mathbf{5}$, Slope $=-\mathbf{0 . 6 5 2}$

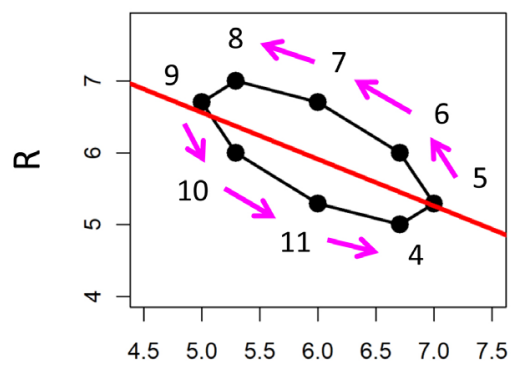

$\mathrm{S}$

(f)

Age-at-maturity $=7$, Slope $=0.641$

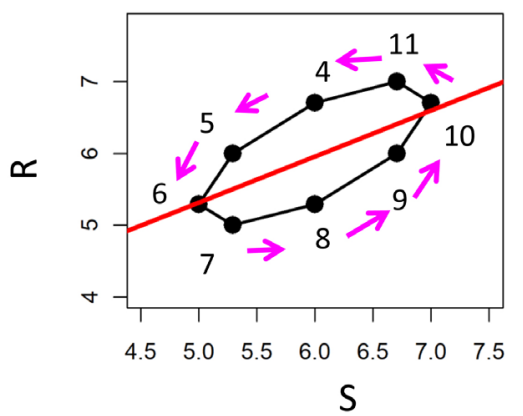

(h)

Figure 2. The eight points of $\left(S_{4}, R_{4}\right),\left(S_{5}, R_{5}\right),\left(S_{6}, R_{6}\right), \ldots,\left(S_{11}, R_{11}\right)$ on the S-R plane are plotted when $m=0,1,2, \ldots, 7$, respectively. The numbers 4 to 11 attached by the points of the SRR trajectory denote the years that construct one cycle. Red line: The regression line adapted to the points. Arrows show the moving direction of each point. 
order, creating a clockwise loop. The lengths of $\mathrm{P} 1$ and $\mathrm{P} 3$ are both 1 year, and the periods of $\mathrm{P} 2$ and $\mathrm{P} 4$ are 3 years; therefore, the loop has a long axis for the northeast or southwest direction. The slope of the regression line thus has a positive value.

Figure $2(b)$ is the graph plotting the eight points $\left(S_{4}, R_{4}\right),\left(S_{5}, R_{5}\right),\left(S_{6}, R_{6}\right), \ldots$, $\left(\mathrm{S}_{11}, \mathrm{R}_{11}\right)$ on the $\mathrm{S}-\mathrm{R}$ plane when $m=1$. When $m=1$, the slope of the regression line is 0.652 , the $95 \%$ confidence interval $(95 \% \mathrm{CI})$ of which is $0.245-1.058$. A significant positive slope is detected and the slope is significantly different from unity.

Figure 1(c) shows the trajectories of the recruitment and $\mathrm{S}$ when the age at maturity is set at 2 . When $m=2$, the time lag between the trajectories of the recruitment and $\mathrm{S}$ is 2 years. In this case the 8 years (one cycle $T$ ) is divided into $\mathrm{P} 1, \mathrm{P} 2, \mathrm{P} 3$ and $\mathrm{P} 4$. The moving direction of the point $(\mathrm{S}, \mathrm{R})$ on the S-R plane in each period is completely the same as those shown in Figure 1(b), and thus a clockwise loop is constructed. In this case, however, the lengths of all four periods are 2 years, and thus the slope of the regression line on the S-R plane becomes zero as shown in the right-hand panel in Figure 1(c).

Figure 2(c) is the graph of the same eight points plotted on the S-R plane when $m=2$. When $m=2$, the slope of the regression line is 0.0785 , the $95 \% \mathrm{CI}$ of which is -0.497 to 0.654 . The slope of the regression line is not significant and it is not different from 0 .

Figure 1(d) shows the recruitment and $\mathrm{S}$ trajectories when the age at maturity is set at 3. In this case the 8 years/one cycle $T$ is divided into P1-P4. In P1, the recruitment increases but the $S$ decreases, and therefore, $(S, R)$ on the $S-R$ plane moves northwest on the $S-R$ plane shown above the trajectories of the figure. The length of $\mathrm{P} 1$ is 3 years. In $\mathrm{P} 2$, the recruitment and $\mathrm{S}$ both increase, and thus point $(S, R)$ on the $S-R$ plane moves northeast on the $S-R$ plane shown above the trajectories. P2 is 1-year long. In P3, the recruitment begins to decrease but the $\mathrm{S}$ still increases, and thus $(S, R)$ on the $S-R$ plane moves southeast on the plane shown above the trajectories. The length of P3 is 3 years. In P4, the recruitment and $\mathrm{S}$ both decrease, and point $(\mathrm{S}, \mathrm{R})$ on the $\mathrm{S}-\mathrm{R}$ plane moves southwest on the $\mathrm{S}-\mathrm{R}$ plane shown above the trajectories in the figure. $\mathrm{P} 4$ is 1-year long.

Therefore, as one cycle passes, a point $(S, R)$ on the S-R plane moves northwest in $\mathrm{P} 1$, northeast in $\mathrm{P} 2$, southeast in $\mathrm{P} 3$, and southwest in $\mathrm{P} 4$, in that order. A clockwise loop is thus constructed. The periods of P1 and P3 are 3 years, and the periods of $\mathrm{P} 2$ and $\mathrm{P} 4$ are 1 year; therefore, the loop has a long axis for the southeast or northwest direction. The slope of the regression line thus has a negative value.

In Figure 2(d), the eight points $\left(S_{4}, R_{4}\right),\left(S_{5}, R_{5}\right),\left(S_{6}, R_{6}\right), \ldots,\left(S_{11}, R_{11}\right)$ are plotted on the S-R plane when $m=3$. When $m=3$, the slope of the regression line is -0.641 , the $95 \%$ CI of which is -1.124 to -0.159 . A significant negative slope is detected and the slope is not significantly different from minus unity.

Figure 1(e) provides the trajectories of the recruitment and $\mathrm{S}$ when the age at 
maturity is set at 4 , i.e., just half of the cycle. When $m=4$, the 8 -year trajectories from years 4 to 11 in one cycle $T$ are divided into two periods. One is the period comprised of 4 years in which the recruitment increases and the $S$ decreases (P1). The other is the 4 years in which the recruitment decreases and the $S$ increases (P2). One cycle is composed of $\mathrm{P} 1$ and $\mathrm{P} 2$.

Figure 1(e) shows the moving direction of a point $(S, R)$ on the $S-R$ plane. In $\mathrm{P} 1$, the direction of vector $\mathrm{S}$ faces the left-hand side (the $\mathrm{S}$ is decreasing), and the direction of vector $\mathrm{R}$ faces the upward direction (the recruitment is increasing). The point then moves northwest. In P2, the direction of vector S faces the right-hand side ( $\mathrm{S}$ is increasing), and the direction of vector $\mathrm{R}$ faces the downward direction (the recruitment is decreasing), and the point moves southeast. Therefore, the point on the S-R plane moves northwest in P1 and southeast in P2 (Figure 1(e), right).

The eight points are plotted on the S-R plane when $m=4$ (Figure 2(e)). When $m=4$, the slope of the regression line is minus unity. As shown at the right of Figure $1(e)$, the points $\left(S_{4}, R_{4}\right)$ move northwest on the S-R plane according to the line of which the slope is minus unity, and then moves southeast along the same line.

Figure $1(\mathrm{f})$ shows the recruitment and $\mathrm{S}$ trajectories when the age at maturity is set at 5 . In this case, the 8-year cycle $T$ is divided into P1-P4. In P1, both the recruitment and $S$ increase, and point $(S, R)$ on the $S-R$ plane thus moves northeast on the S-R plane shown above the trajectories. The length of $\mathrm{P} 1$ is 1 year. In $\mathrm{P} 2$, the recruitment increases but the $S$ decreases, and thus the point $(S, R)$ on the $\mathrm{S}-\mathrm{R}$ plane moves northwest on the plane shown above the trajectories. The length of $\mathrm{P} 2$ is 3 years.

In $\mathrm{P} 3$, both the recruitment and the $S$ decreases, and point $(S, R)$ on the $S-R$ plane moves southwest on the $S-R$ plane shown above the trajectories. The period of $\mathrm{P} 3$ is 1 year. In $\mathrm{P} 4$, the recruitment decreases but the $\mathrm{S}$ increases, and the point $(S, R)$ on the $S-R$ plane moves southeast on the plane shown above the trajectories. P4 is 3 years. As one cycle passes, the point on the S-R plane moves northeast in P1, northwest in P2, southwest in P3, and southeast in P4, constructing an anticlockwise loop. The periods of P1 and P3 are 1 year and those of P2 and P4 are 3 years, giving the loop a long axis for the northwest direction. The slope of the regression line thus has a negative value.

Figure 2(f) plots the eight points on the S-R plane when $m=5$. When $m=5$, the slope of the regression line is -0.652 , the $95 \%$ CI of which is -1.058 to -0.245 . A negative slope is detected and the slope is not significantly different from minus unity.

The recruitment and $S$ trajectories when the age at maturity is set at 6 are shown in Figure $1(\mathrm{~g})$. In this case, the 8-year cycle $T$ is divided into P1-P4. The direction of the movement of point $(S, R)$ on the $S-R$ plane in each period is completely the same as those shown in Figure 1(f), and an anticlockwise loop is constructed. In this case, however, the length of all four periods is 2 years, and 
thus the slope of the regression line on the S-R plane becomes zero.

Figure $2(\mathrm{~g})$ is the plot of the eight points on the S-R plane when $m=6$. When $m=6$, the slope of the regression line is -0.0785 , the $95 \%$ CI of which is -0.654 to 0.497 . The slope of the regression line is not significant and it is not different from 0.

The trajectories of the recruitment and $\mathrm{S}$ when the age at maturity is set at 7 are shown in Figure 1(h). The 8-year cycle $T$ is divided into P1-P4. In P1, both the recruitment and the $S$ increase, and thus point $(S, R)$ on the $S-R$ plane moves northeast on the S-R plane shown above the trajectories. The period of P1 is 3 years. In period $\mathrm{P} 2$, the recruitment increases but the $\mathrm{S}$ decreases, and point $(\mathrm{S}$, $\mathrm{R})$ on the S-R plane moves northwest on the S-R plane. The length of P2 is 1 year. In P3, both the recruitment and the $S$ decrease, so point $(S, R)$ on the $S-R$ plane moves southwest on the $\mathrm{S}-\mathrm{R}$ plane. The $\mathrm{P} 3$ period is 3 years.

In $\mathrm{P} 4$, the recruitment decreases but the $\mathrm{S}$ increases, and point $(\mathrm{S}, \mathrm{R})$ on the $\mathrm{S}-\mathrm{R}$ plane moves southeast on the S-R plane. $\mathrm{P} 4$ is 1 year. Therefore, as one cycle passes, $(\mathrm{S}, \mathrm{R})$ on the $\mathrm{S}-\mathrm{R}$ plane moves northeast in $\mathrm{P} 1$, northwest in $\mathrm{P} 2$, southwest in P3, and southeast in P4, creating an anticlockwise loop. Since the periods of P1 and P3 are 3 years and those of P2 and P4 are 1 year, the loop has a long axis for the northeast direction and the slope of the regression line has a positive value.

In Figure $2(h)$, the eight points $\left(S_{4}, R_{4}\right),\left(S_{5}, R_{5}\right),\left(S_{6}, R_{6}\right), \ldots,\left(S_{11}, R_{11}\right)$ are plotted on the S-R plane for the case of $m=7$. When $m=7$, the slope of the regression line is 0.641 , the $95 \%$ CI of which is $0.159-1.124$. A significant positive slope is thus detected and the slope is not significantly different from unity. When $m$ exceeds the cycle, the same pattern repeats. That is, when $m=8$, the pattern is same of the case of $m=0$, when $m=9$, the pattern is same of the case of $m=1$, and so on.

The results obtained from the above simulations are summarized in Table 1. When the age at maturity is less than half of the environmental cycle, the SRR curves show one clockwise loop for one cycle, and the slope of the SRR changes from plus to minus as the age at maturity increases.

When the age at maturity is greater than the half of the environmental cycle, an anticlockwise loop appears, and the slope changes from minus to plus as the age at maturity increases. That is, the clockwise or anticlockwise nature of the loop and the slope of the regression line for the SRR are determined by the combination of age at maturity and the cycle of environmental fluctuation. When $m$ exceeds the cycle, the same pattern repeats. That is, when $m=8$, the pattern is the same as that in the case of $m=0$ (i.e., $8-T$ ) (where $T$ denotes the environmental cycle and is set at 8 years in the simulation), and when $m=9$, the pattern is the same as that in the case of $m=1($ i.e., $9-T)$, and so on.

\subsection{The Mean Age at Maturity for Pacific Bluefin Tuna}

Figure 3 illustrates the values of $B_{a}$ and $E_{a}$ and the total number of eggs by age. 
Table 1. Age at maturity, slope of the regression line, and the ratio and direction of the loop on the SRR.

\begin{tabular}{|c|c|c|c|c|c|c|}
\hline $\begin{array}{l}\text { Age at maturity } \\
\qquad(m)\end{array}$ & $\begin{array}{l}\text { Slope of the } \\
\text { regression line }\end{array}$ & Ratio $(m / T)$ & $\begin{array}{l}\text { Clockwise or } \\
\text { anticlockwise }\end{array}$ & Corresponding stock & $\begin{array}{l}\text { Slope on the } \\
\text { SRR }\end{array}$ & $\begin{array}{l}\text { 95\% confidence } \\
\text { Intervals }\end{array}$ \\
\hline 0 & $b=1$ & $0 / 8=0$ & Clockwise & & & \\
\hline 1 & $0<b \leq 1$ & $1 / 8=0.125$ & Clockwise & $\begin{array}{c}\text { Pacific stock of Japanese } \\
\text { sardine }\end{array}$ & 0.764 & $(0.634,0.879)$ \\
\hline 2 & $b=0$ & $1 / 4=0.25$ & Clockwise & & & \\
\hline 3 & $-1 \leq \mathrm{b}<0$ & $3 / 8=0.375$ & Clockwise & & & \\
\hline 4 & $b=-1$ & $1 / 2=0.5$ & Anticlockwise & & & \\
\hline 5 & $-1 \leq \mathrm{b}<0$ & $5 / 8=0.675$ & Anticlockwise & & & \\
\hline 6 & $b=0$ & $3 / 4=0.75$ & Anticlockwise & Pacific bluefin tuna & 0.211 & $(-0.048,0.109)$ \\
\hline 7 & $0<b \leq 1$ & $7 / 8=0.875$ & Anticlockwise & & & \\
\hline 8 & $b=1$ & $(8-T) / 8=0$ & Clockwise & & & \\
\hline 9 & $0<b \leq 1$ & $(9-T) / 8=0.125$ & Clockwise & $\begin{array}{c}\text { Western Arctic bluefin } \\
\text { tuna }\end{array}$ & 0.719 & $(0.478,0.959)$ \\
\hline
\end{tabular}
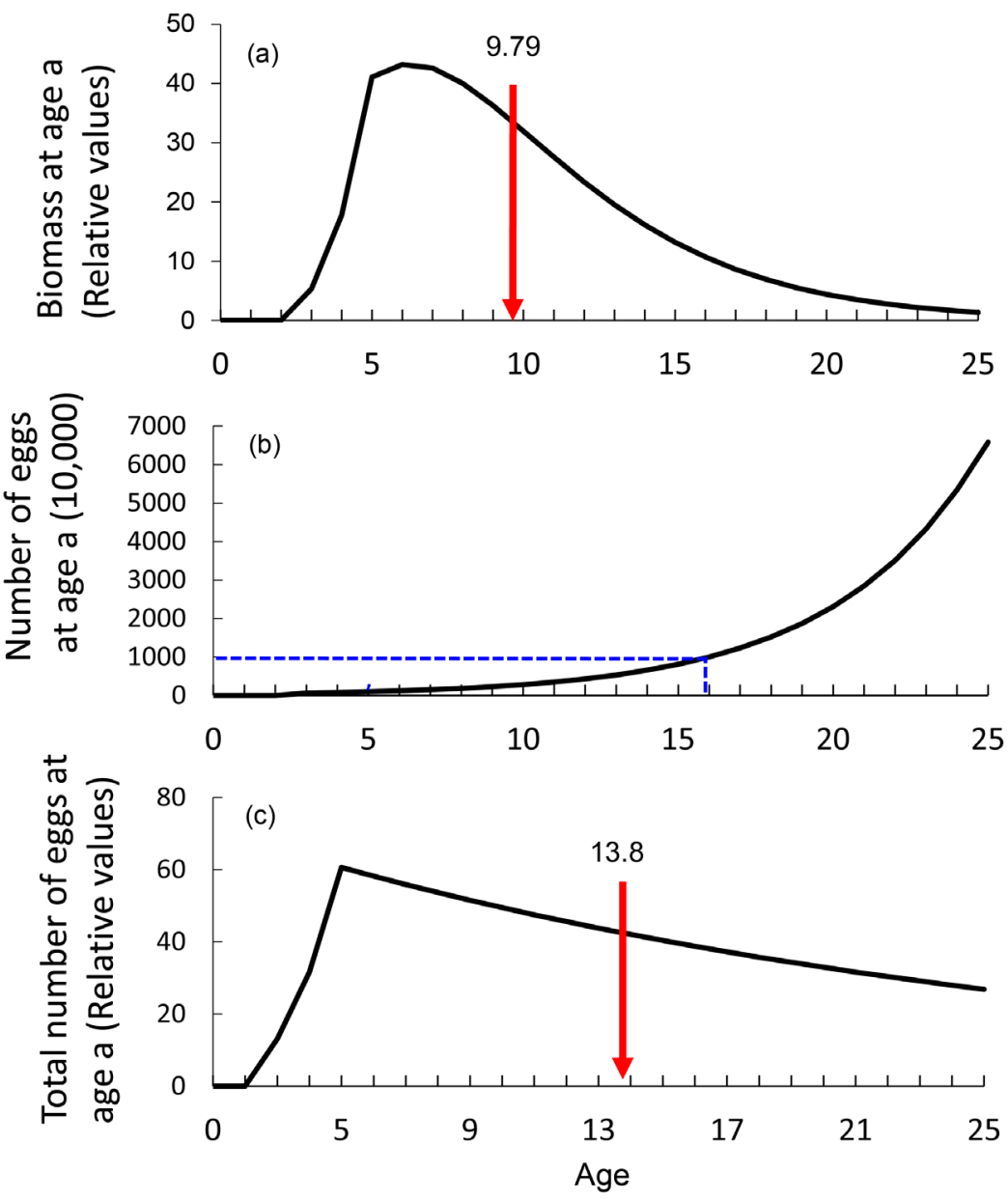

Figure 3. (a) Distribution of the biomass by age for Pacific bluefin tuna. Arrow: The estimated weighted mean age at maturity. (b) Distribution of the number of eggs that one fish spawns. (c) Distribution of the total number of eggs by age. Arrow. The estimated weighted mean age at maturity. 
The mean age at maturity estimated from the distribution of $B_{a}$ values was 9.79 years old, and that estimated from the distribution of the total number of eggs by age was 13.8 years old.

\subsection{The Trajectories of Recruitment and Spawning Stock Biomass (S)}

Figure 4 shows the trajectories of recruitment and $S$ for the Pacific stock of Japanese sardine. The trajectories of recruitment and $S$ can be separated into three periods. The first is 1951 to 1972 (22 years) in which the levels of recruitment and S are low (red). The second is 1973 to 1993 (21 years) in which the levels of recruitment and S are high (blue). The third is 1994 to 2012 (19 years) in which the levels of recruitment and $S$ are medium (green). Figure 5 shows the SRR for the Pacific stock of Japanese sardine. The slope of the regression line for all data was 0.764 , and the $95 \% \mathrm{CI}$ was $0.634-0.874$. That is, the slope is statistically positive but less than unity. The SRR shows three clockwise loops, each of which corresponds to the period low (red), high (blue), and medium (green).

Figure 6 shows the trajectories of recruitment and S for Pacific bluefin tuna. The trajectories of recruitment and $\mathrm{S}$ can be separated into three periods. The first is 1952 to 1969 (18 years) in which the levels of recruitment and S are high (red). The second is 1970 to 1991 (22 years) in which the levels of recruitment and S are low (blue). The third is 1992 to 2012 (21 years) in which the levels of recruitment and S are medium (green). Figure 7(a) shows the SRR for Pacific bluefin tuna. The slope of the regression line for all data was 0.211 , and the $95 \%$ CI was $-0.048-0.109$. That is, the slope is not significantly different from zero. Figure 7(b) shows the SRR for the first two periods (red and blue), and Figure 7 (c) shows the SRR for the third period (green). The SRR shows three anticlockwise loops, each of which corresponds to the periods high (red), low (blue)

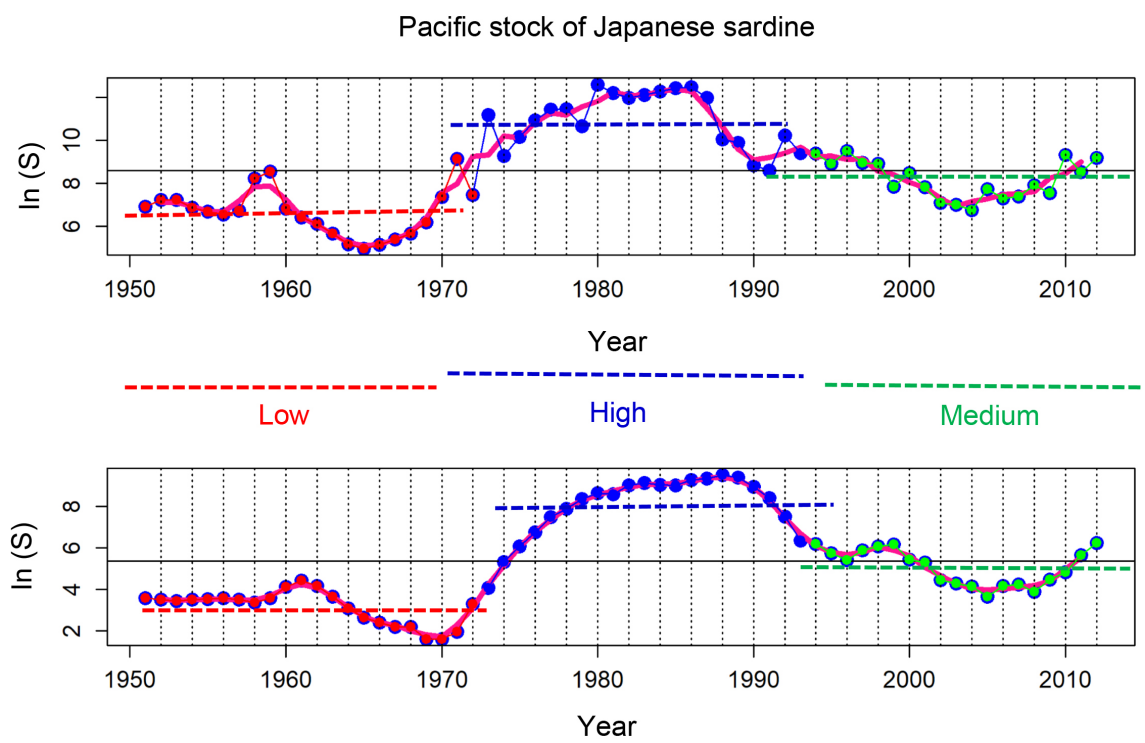

Figure 4. Trajectories of recruitment and S for the Pacific stock of Japanese sardine. The horizontal dotted lines indicate the mean recruitment and $\mathrm{S}$ in each period. 


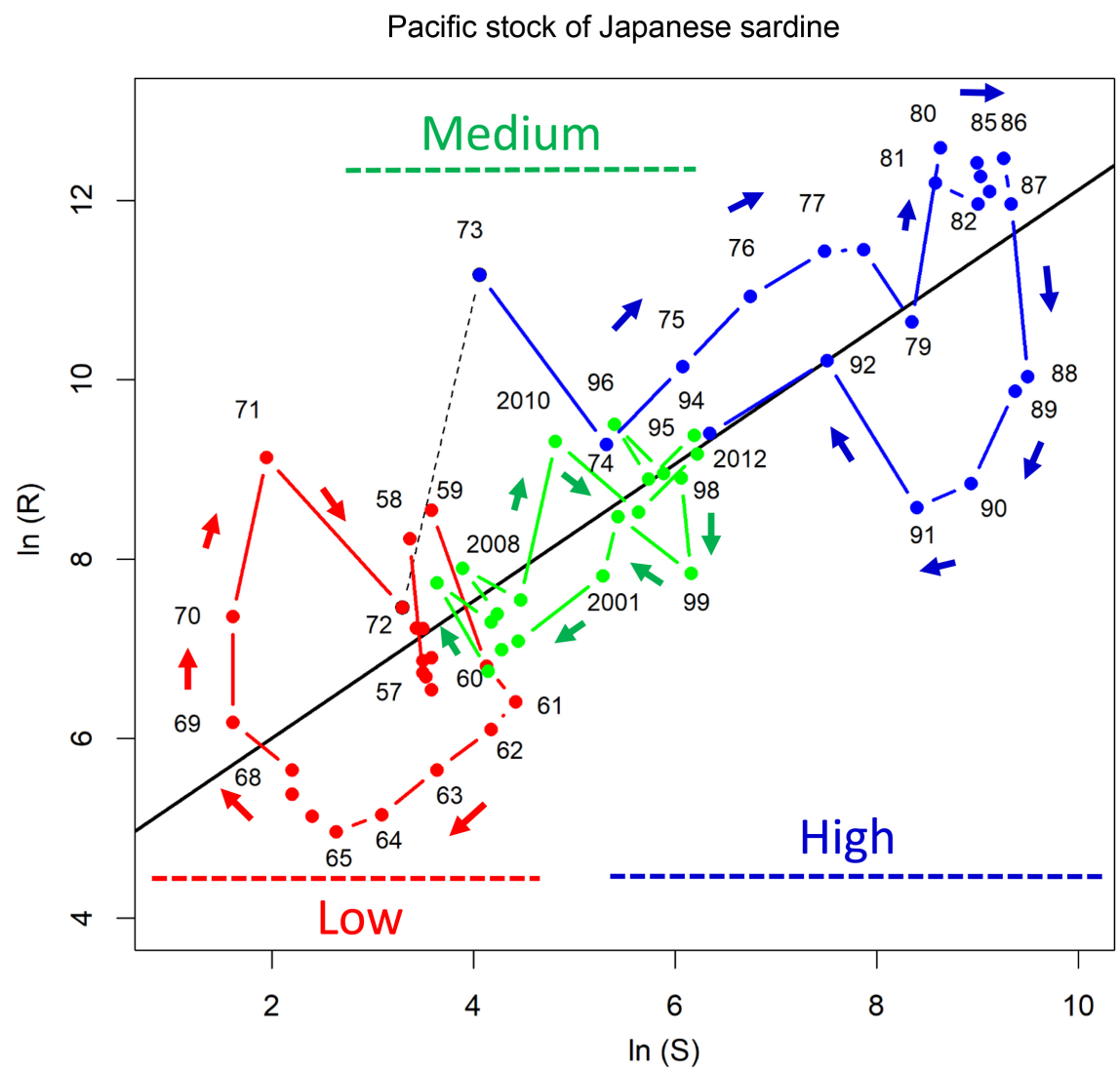

Figure 5. The stock-recruitment relationship (SRR) for the Pacific stock of Japanese sardine. The three colors correspond to the periods shown in Figure 4. In each period, a clockwise loop was recognized.

Pacific bluefin tuna
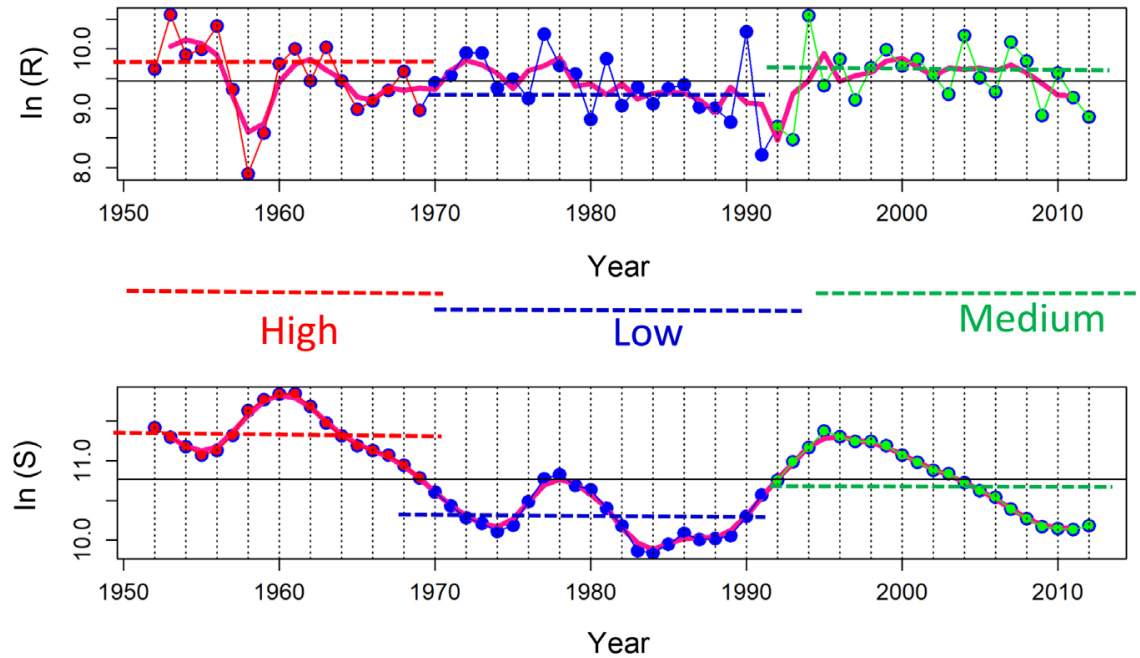

Figure 6. Trajectories of recruitment and S for Pacific bluefin tuna. The horizontal dotted lines indicate the mean recruitment and $S$ in each period.

and medium (green).

Figure 8 shows the trajectories of recruitment and $S$ for Arctic bluefin tuna. 


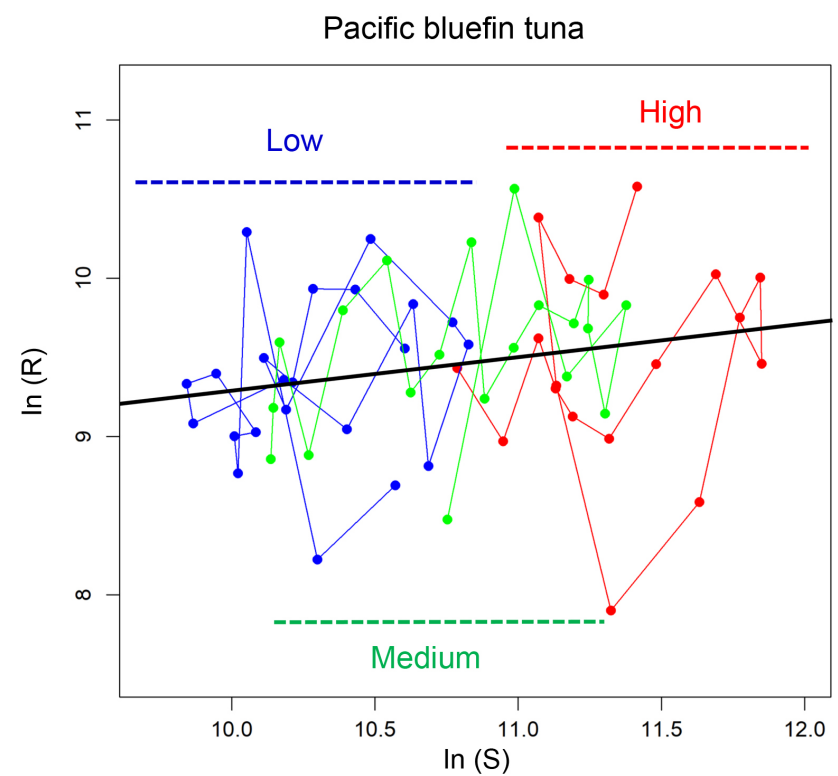

(a)

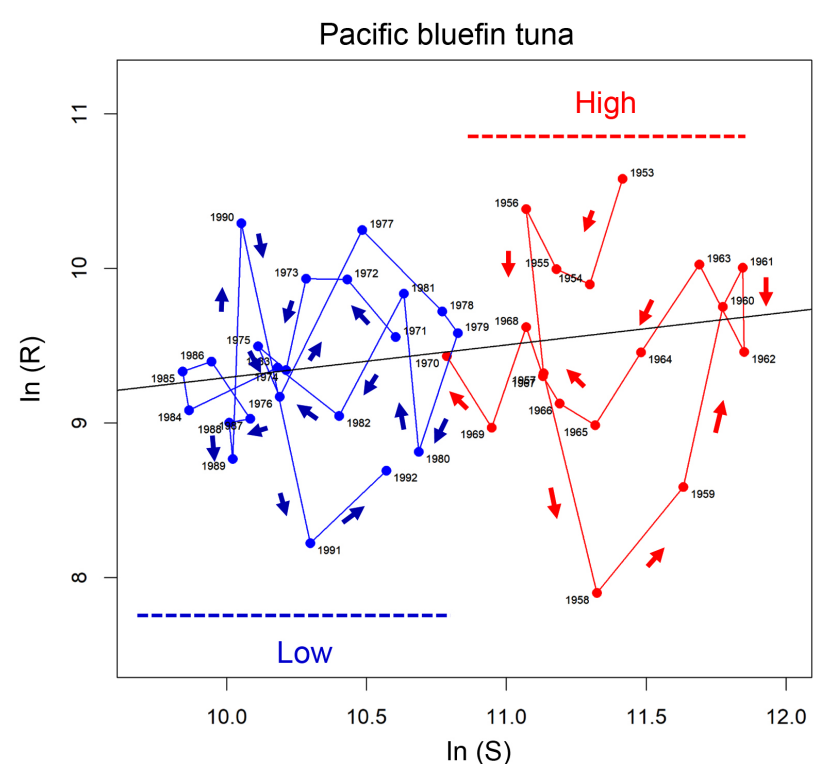

(b)

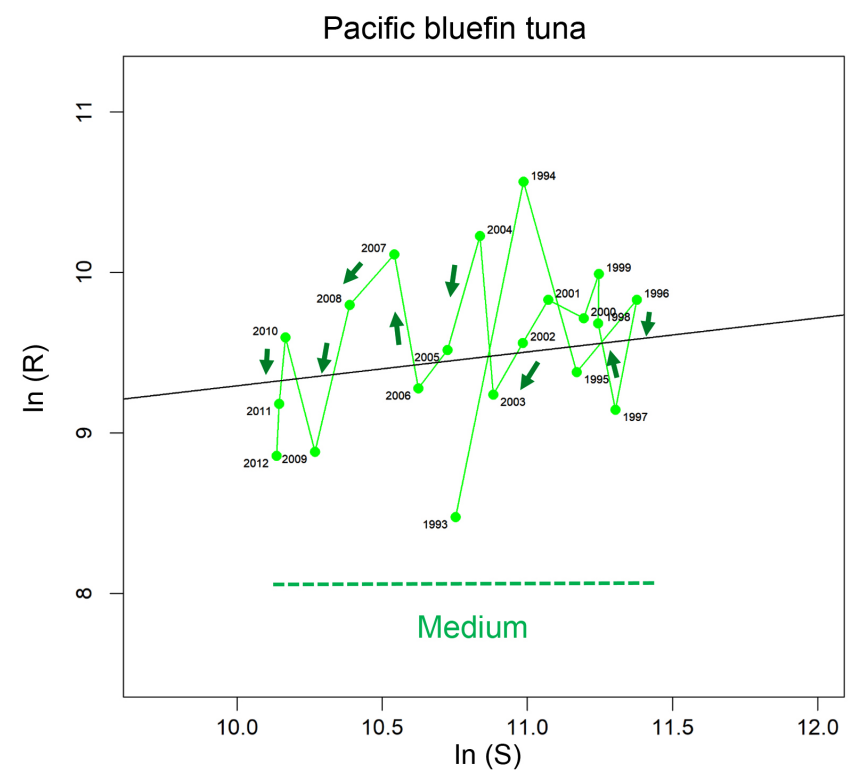

(c)

Figure 7. (a) The SRR for Pacific bluefin tuna. The three colors correspond to the periods shown in Figure 6. The black line is the regression line. The slope was 0.211 and the $95 \%$ CI was $-0.048-0.109$. That is, no relationship between recruitment and S was detected. (b) The SRR for the first two periods. In both periods, anticlockwise loops were recognized. (c) The SRR for the last period. In this period, an anticlockwise loop was recognized.

In this case, I arbitrarily separated the trajectories of recruitment and S into two periods. The first is 1970 to 1988 (19 years) in which the levels of recruitment and S change from high to low. The second is 1989 to 2010 (22 years) in which the levels of recruitment and S are low. Figure 9(a) shows the SRR for Arctic bluefin tuna. The slope of the regression line for all data was 0.719 , and the $95 \%$ CI was $0.478-0.959$. That is, the slope is significantly positive but less than unity. Figure 9 (b) and Figure 9 (c) shows the SRR for the above two periods (red and blue). In both periods, the clockwise loops were recognized. 

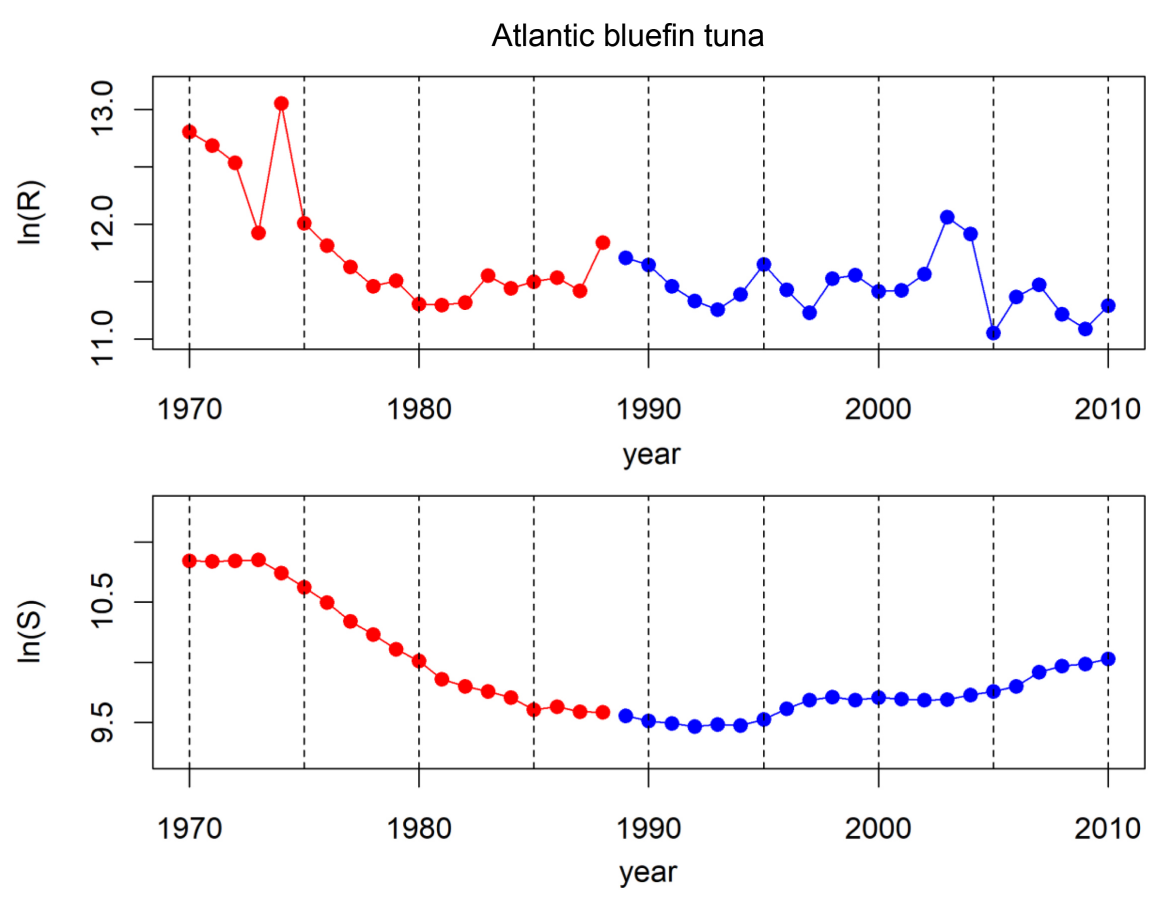

Figure 8. The trajectories of recruitment and $S$ for western Atlantic bluefin tuna. They are separated into two periods to easily show the direction of the loops.

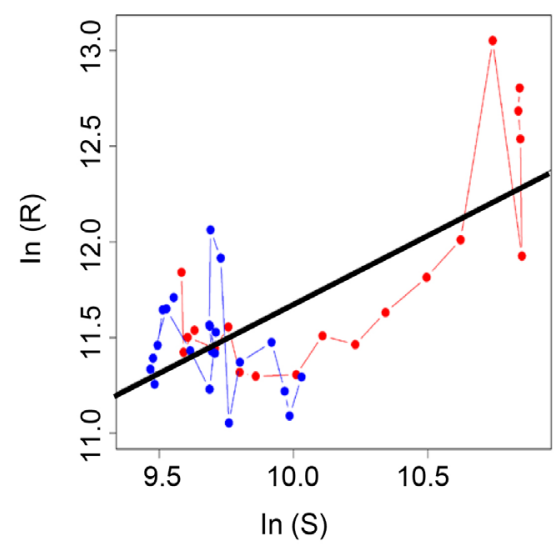

(a)

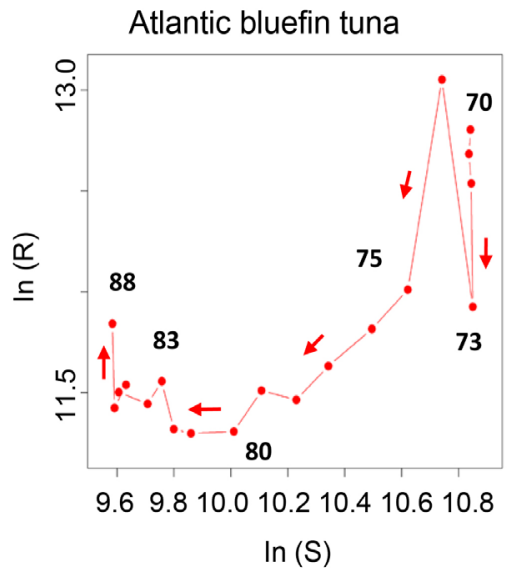

(b)

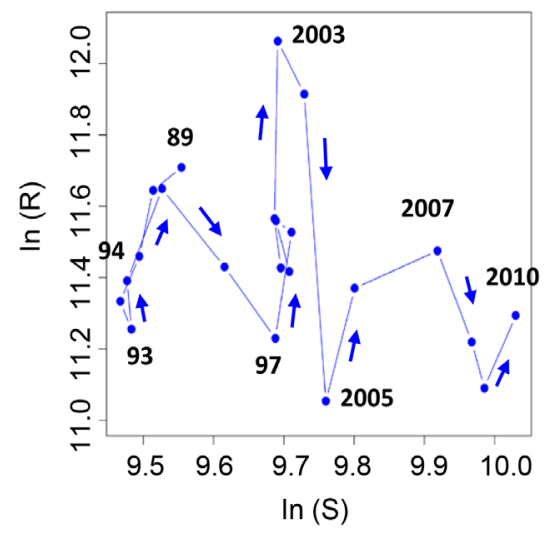

(c)

Figure 9. (a) The SRR for Arctic bluefin tuna. Colors correspond to the periods shown in Figure 8. The black line is the regression line. The slope was 0.719 , and the $95 \%$ CI was $0.478-0.959$. That is, the slope was significantly positive but less than unity. (b) The SRR for the first period. A clockwise loop is recognized. (c) The SRR for the last period. In this period, a clockwise loop is recognized.

\section{Discussion}

\subsection{Validity of the New SRR Model}

In this simulation, to simplify the discussion, I discuss only the process from the recruitment to the $S$; that is, only the survival process from the recruitment to $S$ is considered, not the reproductive process from the $S$ to the recruitment. The SRR is comprised of the reproductive process from spawning stock biomass (S) 
to the recruitment, but when the SRR is discussed, we should treat simultaneously not only the reproductive process from the $S$ to the recruitment, but also the survival process from the recruitment to the S. In other words, those two processes, survival and reproductive processes, cannot be separated in the discussion. I have discussed the details of considering both processes together [11] [15]. That is, the reproductive process from the spawning stock biomass to the recruitment (SRR) and the survival process from the recruitment to the spawning stock biomass can be assumed as follows:

$$
\begin{gathered}
R_{t}=\alpha S_{t} \times f\left(x_{1}, x_{2}, \cdots, x_{k}\right) \\
S_{t+m}=\beta R_{t}
\end{gathered}
$$

Here, $x_{1}, x_{2}, \cdots, x_{k}$ denotes the environmental factors and $f(\cdot)$ is the function that determines the effects caused by environmental factors. That is, the recruitment is proportionally determined by the $\mathrm{S}$ and simultaneously affected by environmental conditions.

The survival process from the recruitment to the $S$ is shown above in Equation (10). Here, $\beta$ is the spawning stock biomass per the recruitment (SPR), which is commonly used in the model analysis. The results of the simulations using Equations (9) and (10) are somewhat complicated, but the essential conclusion is the same as that obtained using Equations (1) and (2). That is, when the age at maturity is low compared to the cycle of the environmental fluctuations, the slope of the regression line in the SRR is near unity with clockwise loops, and when the age at maturity becomes higher, the slope of the regression line in the SRR is near zero or minus. As the age at maturity grows higher compared to the cycle of the environmental fluctuations, the slope of the regression line in the SRR becomes near zero or positive values with anticlockwise loops.

\subsection{The Relationship between Age at Maturity and the Cycle of Environmental Factors}

To simplify the discussion, we assume the use of semelparous fish such as salmon, but iteroparous fishes are common. Therefore, it is better to consider that the age at maturity assumed in the simulation is the mean age at maturity, and it does not mean the first age at maturity. The mean age at maturity for long-longevity fishes must therefore be much longer than the first age at maturity. For example, considering the age at maturity for Pacific bluefin tuna, the maturity rates are $20 \%, 50 \%$ and $100 \%$ for ages 3,4 and $\geq 5$ years old, respectively. However, the fish live more than 20 years. As shown in Figure 3, the mean age at maturity weighted by the biomass is 9.79 years old, and that weighted by the total number of eggs by age is 13.8 years old. As shown in Figures 4-7, it is considered that in the Pacific Ocean, one cycle of the environmental condition is around $18-22$ years. As shown in Table 1, the shape of the SRR is determined by the ratio of the age at maturity to the cycle of the environmental condition. When the ratio is 0.75 ( $m=6$ in Table 1$)$, the slope of the regression line becomes zero with an anticlockwise loop. If the mean age at maturity is 13.8 years 
old and the environmental cycle is around 20 years, the ratio is 0.69 , which is close to 0.75 . This must be the reason why the slope of the regression line for the SRR for Pacific bluefin tuna has no trend and has anticlockwise loops (Figure 7).

Figure 8 shows the SRR for western Atlantic bluefin tuna. The slope of the regression line for western Atlantic bluefin tuna was 0.719, and the $95 \%$ CI was $0.478-0.959$. The slope of the regression line for western Atlantic bluefin tuna is similar to that for the Pacific stock of Japanese sardine, and both SRRs have clockwise loops. The first age at maturity for western Atlantic bluefin tuna is 8 years old and they live for approx. 20 - 30 years. Therefore, the mean age at maturity for this fish must be longer than that for Pacific bluefin tuna. The $100 \%$ matured age for Pacific bluefin tuna is 5 years old and the mean age at maturity is estimated as $9.79-13.8$ years old. That is, the mean age at maturity is estimated to be 2 to 2.76 times larger than the $100 \%$ matured age. If this relation can be applied to the case of western Atlantic bluefin tuna, the mean age at maturity will be around $16-22$ years old. Therefore, the mean age at maturity of western Atlantic bluefin tuna may exceed the cycle of environmental conditions.

Western Atlantic bluefin tuna and Pacific bluefin tuna are different species, and their habitats differ. However, the ecological similarity of these two species seems to be much higher than that of the Pacific stock of Japanese sardine, even though the shape of the SRR for western Atlantic bluefin tuna is similar to that for the Pacific stock of Japanese sardine, but not similar to the SRR for Pacific bluefin tuna. I believe that this phenomenon can only be explained by the mechanism proposed in this paper.

The age at maturity seems to be determined on a species-by-species or stock-by-stock basis. However, even in the same species, the environmental conditions that affect the population fluctuations are different in different habitats. Further, even in the same habitat, the length of the environmental cycle itself changes era by era. Therefore, whether or not the SRR has clockwise or anticlockwise loops is determined not only by the stock but also by its era. That is, even for same species, the shape of the SRR can be changeable depending on the era. When a period in which the environmental conditions are relatively stable is long, the slope of the regression line on the SRR is close to unity and the direction of the loop tends to be clockwise. Conversely, when a period with stable environmental conditions is short, the slope of the regression line on the SRR decreases to zero or minus, and the direction of the loop tends to be anticlockwise. Therefore, when we analyze actual data, we should focus on the cycle of the environmental conditions that affect the fluctuation in recruitment.

\section{Conclusions}

The results elucidated in this paper can be summarized as follows:

1) When the age at maturity is less than half of the environmental cycle, the SRR curve shows one clockwise loop for one cycle. When the age at maturity is greater than half of the environmental cycle, the SRR curve shows one anti- 
clockwise loop for one cycle.

2) The slope of the regression line for the SRR is determined by the age at maturity. When the age at maturity is low compared to the cycle of the environmental fluctuations, the slope of the regression line has a positive value with clockwise loop, and when the age at maturity is high compared to the cycle of the environmental fluctuations, the slope of the regression line has no trend with anticlockwise loop.

3) The SRR for the Pacific stock of Japanese sardine corresponds to the case when $m=1$ in the simulation. The SRR for the Pacific bluefin tuna corresponds to the case when $m=6$ in the simulation. The SRR for the Arctic bluefin tuna corresponds to the case when $m=9$ in the simulation.

\section{References}

[1] Ricker, W.E. (1954) Stock and Recruitment. Journal of the Fisheries Research Board of Canada, 11, 559-623. https://doi.org/10.1139/f54-039

[2] Beverton, R.J.H. and Holt, S.J. (1957) On the Dynamics of Exploited Fish Populations Fishery Investigations, Series II 19 [1-533]. Her Majesty's Stationery Office, London.

[3] Shepherd, J.G. (1982) A Versatile New Stock-Recruitment Relationship for Fisheries, and the Construction of Sustainable Yield Curves. Journal du Conseil International Pour Exploration de la Mer, 40, 67-75. https://doi.org/10.1093/icesjms/40.1.67

[4] Pacific Bluefin Tuna Working Group (PBFWG) (2014) Stock Assessment of Pacific Bluefin Tuna 2014. Report of the Pacific Bluefin Tuna Working Group. International Scientific Committee for Tuna and Tuna-Like Species in the North Pacific Ocean, 1-121.

[5] Standing-Committee on Research and Statistics (2014) ICCAT Report of the Standing-Committee on Research and Statistics (SCRS). Madrid, Spain, 2-6 October 2014.

[6] Standing-Committee on Research and Statistics (2017) ICCAT Report of the Standing-Committee on Research and Statistics (SCRS). Madrid, Spain, 2-6 October 2017.

[7] Sakuramoto, K. (2005) Does the Ricker or Beverton and Holt Type of Stock-Recruitment Relationship Truly Exist? Fisheries Science, 71, 577-592. https://doi.org/10.1111/j.1444-2906.2005.01002.x

[8] Sakuramoto, K. (2013) A Recruitment Forecasting Model for the Pacific Stock of the Japanese Sardine (Sardinops melanostictus) That Does Not Assume Density-Dependent Effects. Agricultural Sciences, 4, 1-8. https://doi.org/10.4236/as.2013.46A001

[9] Sakuramoto, K. (2014) A Common Concept of Population Dynamics Applicable to both Thrips imaginis (Thysanoptera) and the Pacific Stock of the Japanese Sardine (Sardinops melanostictus). Fisheries and Aquatic Sciences, 4, 140-151.

[10] Sakuramoto, K. (2015) Illusion of a Density-Dependent Effect in Biology. Agricultural Sciences, 6, 479-488. https://doi.org/10.4236/as.2015.65047

[11] Sakuramoto, K. (2015) A Stock-Recruitment Relationship Applicable to Pacific Bluefin Tuna and the Pacific Stock of Japanese Sardine. American Journal of Climate Change, 4, 446-460. https://doi.org/10.4236/ajcc.2015.45036 
[12] Sakuramoto, K. (2016) A Simulation Model of the Spawning Stock Biomass of Pacific Bluefin Tuna and Evaluation of Fisheries Regulations. American Journal of Climate Change, 5, 245-260. https://doi.org/10.4236/ajcc.2016.52021

[13] Sakuramoto, K. (2016) Density-Dependent Effect Occurs Regardless of Density. Open Access Library Journal, 3, e3112. https://doi.org/10.4236/oalib.1103112

[14] Tanaka, K., Suzuki, N. and Sakuramoto, S. (2017) Clockwise Loops and Anticlockwise Loops Observed in a Stock-Recruitment Relationship. Open Access Library Journal, 4, e3688.

[15] Sakuramoto, K. (2017) Are $20 \% \mathrm{~B}_{0}, 20 \% \mathrm{~B}_{\text {unfished }}$, and $\mathrm{B}_{\mathrm{MSY}}$ Valid as Reference Points for Fisheries Resource Management? Open Access Library Journal, 4, e3897. https://doi.org/10.4236/oalib.1103897

[16] Myer, R.A., Rosenberg, A.A., Mace, P.M., Barrowman, N. and Restrepo, V.R. (1994) Is Search of Thresholds for Recruitment Overfishing? The ICES Journal of Marine Science, 51, 191-205. https://doi.org/10.1006/jmsc.1994.1020

[17] Kawabata, J., Honda, S., Watanabe, C., Okamura, H. and Ichinokawa, M. (2014) Stock Assessment and Evaluation for the Pacific Stock of Japanese Sardine (Fiscal Year 2013). In: Marine Stock Fisheries Stock Assessment and Evaluation for Japanese Waters (Fiscal Year 2013/2014), Fisheries Agency and Fisheries Research Agency, Japan, 15-46.

[18] Yatsu, A., Watanabe, T., Ishida, M., Sugisaki, H. and Jacobson, L.D. (2005) Environmental Effects on Recruitment and Productivity of Japanese Sardine Sardinops melanostictus and Chub Mackerel Scomber japonicus with Recommendations for Management. Fisheries Oceanography, 14, 263-278.

https://doi.org/10.1111/j.1365-2419.2005.00335.x 